SHORT REPORT

\title{
Hospital youth work and adolescent support
}

\section{A R Watson}

$\mathrm{T}$ his paper describes the development of a youth worker role in providing young people with more appropriate care and support in the hospital setting. Recent reports have highlighted the increasing use of hospital beds through adolescence and the paucity of facilities and support that adolescent patients encounter. ${ }^{1-3}$ Adolescent patients are recognised as having a number of problems related to their stage of development in addition to those associated with chronic illness. Educational opportunities may be lost, self esteem may suffer, and social relationships may be adversely affected. ${ }^{4}$ There may be major issues with non-adherence to treatment..$^{5-8}$ Increasingly successful treatments for childhood chronic illness means an increasing number of young people will be facing the transition from paediatric to adult units with all the attendant problems. ${ }^{9-13}$

Like many paediatric units, we had renamed ourselves as a Children \& Young People's Unit and developed an adolescent policy document. However, there was an insufficient throughput of patients to warrant the development of a unit for young people only, and there were few nurses on the ward with any experience of adolescent nursing. We proposed employing a youth worker as part of our multiprofessional team to:

- Improve the advocacy for this group of patients

- Assist in the implementation of the adolescent policy

- Encourage the personal development of young people with both educational and leisure opportunities

- Assist in the transition to adult care.

\section{WHAT IS YOUTH WORK?}

Youth workers work mainly with young people between 11 and 25 years of age in the community and aim to promote their personal and social development with a range of informal educational activities which combine enjoyment, challenge, and learning. ${ }^{14}$ The increasing importance of youth work has recently been stressed by the UK government. ${ }^{15}$

Our team members felt that young people with chronic illness would benefit from the four key components of good youth work-that is, personal support, promoting the young people's viewpoints, providing a diverse range of personal and social developmental opportunities, and promoting self esteem and optimism. We had already highlighted inadequacies in our transition process to adult units and we hoped the youth worker would assist developments in this area. ${ }^{710}$

\section{RECRUITMENT OF A HOSPITAL YOUTH WORKER}

With the availability of two years' charity funding we advertised for a youth worker to work initially within the Children \& Young People's Kidney Unit. The Diploma of Higher Education in Youth and Community Development Work (recognised by the Joint Negotiating Committee for Youth and Community Workers) and two years' experience in the community were essential. We had a number of responses to our advertisement but none of the applicants had had any previous hospital experience. The Senior Paediatric Nurse Manager was part of the recruitment panel and recommended the appointment on the nursing $\mathrm{F}$ grade scale ( $£ 19000-£ 23500 \mathrm{pa})$. Nationally qualified full time youth workers in local authority employment are paid on a three level salary scale. ${ }^{14}$ The full time youth worker would work a 37 hour week with flexible time for evening and weekend sessions.

\section{TRAINING}

The youth worker followed an induction period of four weeks' observing and meeting with other members of our renal multiprofessional team as well as meeting with staff on other wards. Individuals who join the team from outside the hospital often state that it takes at least six months to integrate fully into the workings of a chronic illness team. We were aware from appointments elsewhere that if a youth worker was appointed with no specific attachment to any one team, then it becomes very difficult for contacts and confidence in that person's work to be established. If the youth worker is going to be responsible for young people from a number of units, then it is recommended that they spend an induction period of at least a month with each chronic illness team so that contacts are well established and the youth worker has a good understanding of the expectations and problems in each area. Mentoring in the first two years was by senior paediatric nurse managers and the unit medical director.

\section{WORK UNDERTAKEN BY YOUTH WORKER}

As well as assisting in the implementation of the adolescent policy and practical developments such as the provision of a youth room and youth club, the youth worker has been involved in many other areas over the past four years. These are shown in box 1 and described in more detail elsewhere. ${ }^{16}$

\section{HOW DO YOU ASSESS BENEFIT?}

In the community the quality of youth work is monitored and evaluated through inspections by Her Majesty's Inspectorate (Office for Standards in Education (Ofsted) UK). Formal appraisal of the hospital youth worker post took place at six and 18 months prior to the end of the two year charity funding by the senior nurse manager and unit director. The appraisals took into account the views of all members of the multiprofessional team as well as the annual report the youth worker produced detailing her activities and range of contacts with young people.

Informal feedback from the young people and their families at clinic visits has been most supportive and a questionnaire survey of young people before and one year later about their needs has emphasised how the youth worker has provided valuable counselling on many issues both night and day. ${ }^{17}{ }^{18}$ Residential weekends have been held at youth hostels and not only help to build peer support and self esteem, but also provide an opportunity to explore the views and issues that concern young people. ${ }^{19}$ Already in the 


\section{Box 1 Areas developed by youth worker}

\section{General development}

- Adolescent policy development

- Young people's hospital information pack

- Young people's multidisciplinary special interest group

- Youth work section of unit newsletter

- Youth room on ward

- Hospital youth club two evenings a week

Individual support

- Personal advice on health, educational, and family issues

- Accompanying young people for interviews and other hospital appointments

- Advocacy work on wards

\section{Group work}

- Organised outings with inclusion of siblings

- Residential holidays

- Projects with groups of haemodialysis patients

- Establishment of a youth committee with young people having different chronic illnesses

- Transition project with involvement of those already transferred to adult care

- Educational projects; e.g. Youth Achievement Awards

first two years young people who were leaving the unit for adult centres offered to return as volunteers to provide peer support for other young people about to undergo transition.

The formal assessment resulted in the youth work post being formally adopted within the paediatric directorate budget at two years and expanding her role to support young people with diabetes, cystic fibrosis, chronic asthma, and surgical conditions. The whole of the Children \& Young People's Unit has 65 beds, with approximately 2873 admissions and 1740 new outpatient attendances per year. In 2001, 131 young people in the 10-18 age group had had contact with the youth work project at some time, with $62 \%$ having had more than one contact. Fifteen young people have been enrolled for Youth Achievement Awards which are available to young people aged 14-20 plus. The awards range from bronze to platinum and are designed to recognise young people's achievement and learning with participative youth work. ${ }^{20}$ Five patient volunteers have also enlisted on a course on "Introductory studies in informal and community education".

It is already obvious after four years that a single handed youth worker requires colleague support, and one part time youth work assistant has been employed with charity funding. Male youth worker volunteers (students doing youth work courses) are also being recruited as it is recognised that self esteem, peer pressure, identity, and coping styles all have gender elements. ${ }^{21}$

\section{SUPPORTING THE VOICE OF YOUNG PEOPLE}

The young people were encouraged to form their own youth work committee and embarked on major fundraising events to raise money for the development of a youth room on the ward. Several completed the demanding 140 mile bicycle ride from coast to coast across northern England. Additional money was found to provide an office for the youth worker so that she has more privacy both for her counselling work and also for the teaching of youth work volunteers and trainees who are increasing in number.

The same youth committee produced a video which so impressed a local company that they provided funding for the formation of a hospital youth club. This is almost unique in the UK and is now well established two evenings a week, with an increasing number of young people travelling long distances to attend. It is supported by the local community youth work service and its attendance rate is better than at most local community youth clubs. Members of the committee were also invited to speak at a national conference, "Involving Young People in the NHS" in York, UK in September 2002, and two members have also been invited to join a national organisation, the Carnegie Young People Initiative, which aims to "increase the breadth and improve the quality of work to involve young people aged 10-25 in the key public decisions which affect their lives". ${ }^{22}$

\section{LEARNING POINTS}

Points other units may consider when appointing a youth worker are shown in box 2 .

The youth worker in hospital can act as a roving ambassador for young people throughout the unit, especially when there is no geographically defined adolescent unit as such. There is no doubt that these young people, especially those with chronic illness, need support, not only on a one to one basis but also through group work and educational opportunities. The benefits that we have seen locally lead us to believe that the youth worker is an essential part of a Children \& Young People's Unit.

\section{Box 2 Points to consider when appointing a} youth worker

- There must be a clear understanding of the role and breadth of youth workers so that they are not regarded as "nursery nurses for teenagers"

- There should be a clear induction programme so that the youth worker can integrate into the multiprofessional team and everyone gain an understanding of his/her role

- The youth worker will need mentoring and support within the hospital, but will also need to maintain links with the local Youth Service and be aware of professional developments

- The youth worker will need time to use their skills to advocate and shape the support service for young people in hospital

- Working with young people is a process, and building up relationships of trust can take time; problems cannot be solved in an instant

- Regular meetings should be arranged with ward representatives and management for feedback on issues and to discuss developments such as the young people's policy

- The youth worker should be encouraged to provide an annual report of progress to emphasise the development of the role

- If successful the youth worker will probably need additional support within two years 
"Youth work changes lives ... There are few more important investments than in the future of young people, and few better ways of delivery change than through good youth work." (David Blunkett, then Secretary of State for Education and Employment, 2001)14

\section{ACKNOWLEDGEMENTS}

I thank Donna Hilton, Youth Worker, for her enthusiasm and comments, and Judith Hayes for help with typing the manuscript.

Correspondence to: Dr A R Watson, Children \& Young People's Kidney Unit, City Hospital, Hucknall Road, Nottingham NG5 1PB, UK;

jhayes1@ncht.trent.nhs.uk

Accepted 5 June 2003

\section{REFERENCES}

1 Viner RM. National survey of use of hospital beds by adolescents aged 12 to 19 in the United Kingdom. BMJ 2001;322:957-8.

2 Suresh S, Doull IJM, Thomas P. Adolescent inpatient units. Arch Dis Child 2000;82:266.

3 Hampson L. Adolescent health care: the Irish experience. Paediatr Nurs 2000;12:21-5.

4 Walco GA, Lewis GR, Schmerl LT. Psychosocial aspects of coping with chronic illness in adolescent medicine. In: Shanker IR, ed. Adolescent medicine. Switzerland: Harwood Academic Publishers, 1994:261-78.

5 Matsui DM. Drug compliance in pediatrics. Pediatr Clin North Am 1997;44:1-14.
6 Staples B, Bravender T. Drug compliance in adolescents: assessing and managing modifiable risk factors. Pediatr Drugs 2002;4:503-13.

7 Watson AR. Non-compliance and transfer from paediatric to adult transplant unit. Pediatr Nephrol 2000;14:469-72.

8 Schidlow DV. Concordance and compliance. British guidelines on the management of asthma. Thorax 2003;58(suppl 1):159-60.

9 Schidlow DV, Friel SB. Life beyond paediatrics: transition of chronically ill adolescents from pediatric to adult health care systems. Med Clin North Am 1990;74:1113-20

10 Watson AR, Phillips D, Argles J. Transferring adolescents from paediatric to adult renal units. Br J Renal Med 1996; 1:24-6.

11 Viner R. Transition from paediatric to adult care. Bridging the gaps or passing the buck? Arch Dis Child 1999;81:271-5.

12 McDonagh JE. The adolescent challenge. Nephrol Dial Transpl 2000;15:1761-5.

13 Webb AK, Jones AW, Dodd ME. Transition from paediatric to adult care: problems that arise in the adult cystic fibrosis clinic. J $R$ Soc Med $2001 ; 94$ (suppl 40):5-7.

14 NYA. Guide to youth work and youth services. The National Youth Agency: Leicester, UK, 2002. www.nya.org.uk.

15 Anon. Transforming youth work. www.connexions.gov.uk/publi.htm.

16 Hilton D, Watson AR, Walmsley P, et al. Youth work in hospital. Paediatr Nurs 2004; 16:36-9.

17 Burke T. Awards on the ward. Young People Now July 2002:24-5.

18 Young K. The art of youth work. Russell House Publishing, 1999.

19 Williams $\mathbf{H}$. On the road again. Young People Now NYA Leicester 1998;111:24-6.

20 Youth Clubs UK. The Youth Achievement Awards. London. http:// web.ukonline.co.uk/youthclubs.uk.

21 Lloyd T, Forrest F. Boys' and young men's health. Health Development Agency: London, 2001. www.had-online.org.uk/yphn.

22 Cutler D. Taking the initiative: promoting young people's involvement in public decision making in the UK. The Carnegie Young People's Initiative: London, 2002. www.carnegie-youth.org.uk.

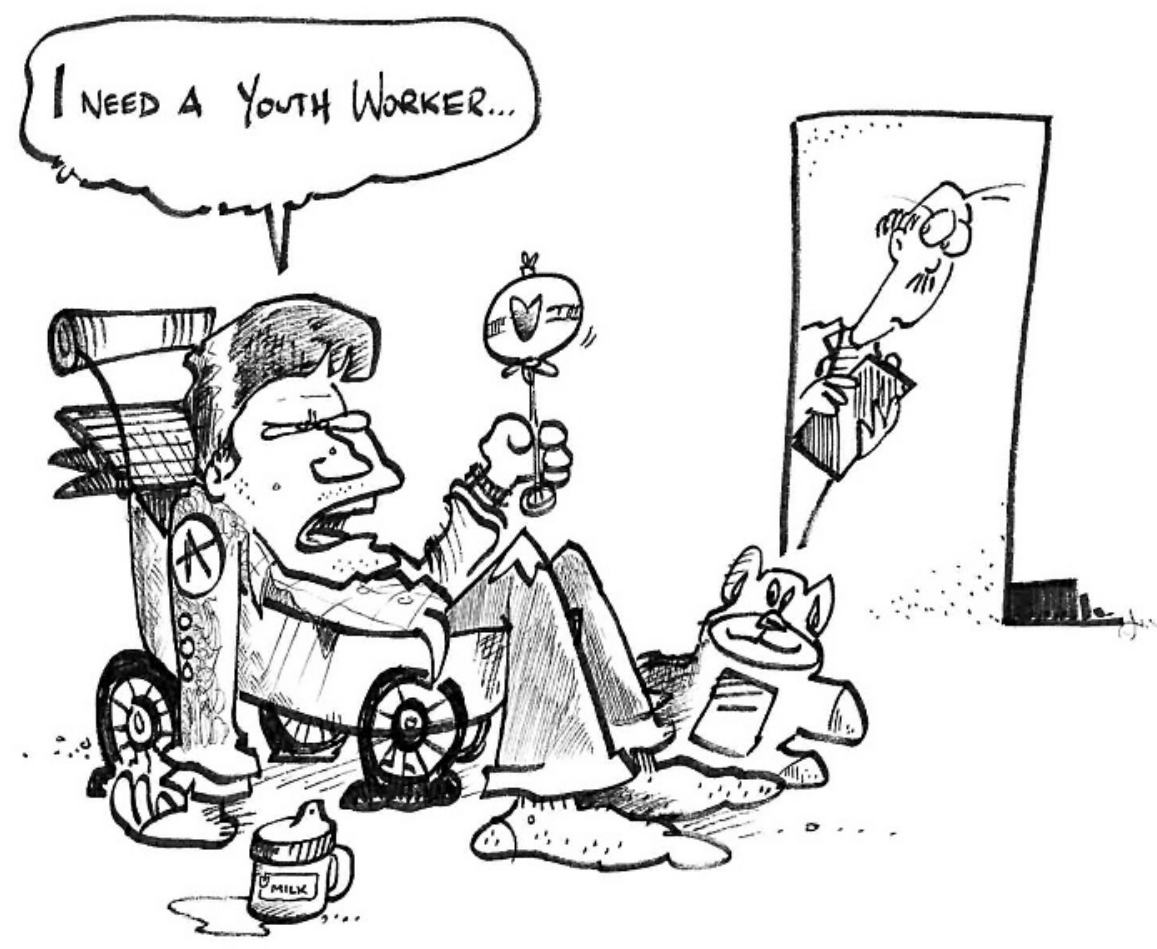

